\title{
El efecto de la descentralización fiscal sobre el crecimiento, la inflación y la desigualdad en América
}

\author{
Antonio N. Bojanic ${ }^{1}$
}

\section{Resumen}

En este artículo se analiza el efecto de la descentralización fiscal en el crecimiento económico, la inflación y el coeficiente de Gini en 12 países de América. Las conclusiones sugieren que el efecto positivo de este proceso ha sido más modesto de lo previsto, que la descentralización de los ingresos tiene un efecto perjudicial en el crecimiento económico y la descentralización de los gastos uno positivo en los países en desarrollo de América. En cuanto al efecto sobre la desigualdad de los ingresos, la descentralización fiscal puede desempeñar un papel importante para reducirla. No obstante, cuando la descentralización fiscal se analiza solo en los países en desarrollo de América, se observa que esta acentúa la desigualdad de los ingresos en lugar de mitigarla. Las conclusiones relativas al efecto de la descentralización fiscal sobre la estabilidad de los precios no son concluyentes.

\section{Palabras clave}

Política fiscal, administración fiscal, descentralización gubernamental, crecimiento económico, inflación, distribución del ingreso, estabilización de precios, medición, América del Norte, América Latina

\section{Clasificación JEL}

E62, H70, O10, O50

\section{Autor}

Antonio N. Bojanic es Profesor de Práctica en el Departamento de Economía de la Universidad de Tulane. Correo electrónico: abojanic@tulane.edu. 


\section{Introducción}

En la mayoría de los países de América Latina, en los últimos tres decenios una parte considerable de las actividades y funciones de gobierno se han devuelto a las estructuras gubernamentales subnacionales, en particular a las de nivel regional, municipal y local. Entre los motivos de esta tendencia a descentralizar las actividades de gobierno se encuentran los siguientes: democracias más maduras y arraigadas, cuyas instituciones reflejan cada vez más las necesidades de circunscripciones específicas; el deseo de que distintos subgrupos y regiones dentro de las sociedades estén más representados, y la constatación de que se puede lograr una mayor eficiencia al transferir las responsabilidades a las zonas y las comunidades que las intervenciones gubernamentales afectan de forma más directa.

El tema principal de este estudio es la descentralización fiscal, que ocurre cuando los gobiernos centrales transfieren determinadas responsabilidades asociadas con los ingresos y los gastos a los niveles subnacionales de gobierno. La mayor parte de la investigación económica sobre este tema se ha centrado en la forma en que la descentralización fiscal afecta la gobernanza y el crecimiento económico, pero en los últimos tiempos se han comenzado a analizar las maneras en que afecta la pobreza, la distribución del ingreso y los derechos fundamentales, entre ellos los derechos civiles y políticos, así como la libertad económica.

Si bien en las investigaciones actuales se ha estudiado de forma exhaustiva cómo repercute la descentralización en el crecimiento, no se ha llegado a conclusiones claras, en particular cuando el proceso de descentralización se analiza desde la perspectiva de los países en desarrollo. La falta de datos concluyentes se hace aún más evidente cuando se examinan los efectos de la descentralización en otras variables, como la distribución del ingreso y la estabilidad económica. Este documento tiene por objeto contribuir a subsanar algunas de las deficiencias de la investigación actual, al analizar el efecto que la descentralización fiscal ha tenido sobre el crecimiento económico, la inflación y la desigualdad de los ingresos en una región del mundo, América $^{2}$, donde la cuestión de la descentralización ha estado al frente de las reformas estructurales durante varios decenios.

El resto del documento se organiza de la siguiente manera. En la sección II se presenta un breve examen de la literatura sobre la relación entre la descentralización fiscal, el crecimiento, la estabilidad económica y la desigualdad. En la sección III se presentan los argumentos teóricos de las previsiones relativas a los efectos de la descentralización en las principales variables de interés. En la sección IV se presentan los datos y la metodología, y en la sección V se analizan los resultados empíricos. En la sección VI se resumen las principales conclusiones y se examinan sus consecuencias en materia de políticas.

\section{Examen de la literatura}

Una de las principales esferas de investigación económica en materia de descentralización fiscal se refiere a los efectos que esta tiene sobre el crecimiento económico. Esta cuestión se ha analizado en diversos estudios que abarcan varios países o países individuales que, en su mayoría, aunque no exclusivamente, son países desarrollados. Un tema que se relaciona con el anterior es la manera en que la descentralización ha afectado la estabilidad económica, y también ha habido una importante labor de investigación sobre este asunto. Las áreas de interés más recientes son los efectos en la pobreza, la desigualdad de los ingresos y las libertades humanas fundamentales. A continuación se presenta un breve examen de algunos de los trabajos más importantes referidos a esta serie de temas.

2 En este artículo, el término "América" comprende a países en América del Norte, Centroamérica y América del Sur. 
Hay muchos estudios en los que se ha analizado la forma en que la descentralización fiscal repercute en el crecimiento económico de varios países. Entre los primeros aportes importantes se encuentra el de Davoodi y Zou (1998), que trabajaron con datos de 46 países y hallaron una correlación negativa entre la descentralización fiscal y el crecimiento en los países en desarrollo, pero no en las economías desarrolladas. Martínez-Vázquez y McNab (2003) llegaron a la conclusión de que, si bien la descentralización fiscal podría tener un efecto en el crecimiento, los fundamentos teóricos de esta relación todavía no estaban bien desarrollados y, por lo tanto, no se podía proporcionar una respuesta definitiva. Martínez-Vázquez y McNab (2006) concluyeron que, cuando se hallaba una correlación negativa entre la descentralización y el crecimiento en los países desarrollados, esta podía ser contrarrestada por el efecto positivo de la descentralización en la estabilidad macroeconómica. Thornton (2007) trabajó con datos de 19 países de la Organización de Cooperación y Desarrollo Económicos (OCDE) y determinó que, cuando para medir la descentralización fiscal solo se empleaban los ingresos sobre los cuales los gobiernos subnacionales tenían plena autonomía, el efecto de la descentralización en el crecimiento económico no era estadísticamente significativo.

Entre los estudios más recientes se encuentra el de Rodríguez-Pose y Ezcurra (2011), en el que se examina un conjunto de 21 países de la OCDE y se halla una considerable asociación negativa entre la descentralización fiscal y el crecimiento económico, a pesar de que se incluyeron varios ajustes y variables de control para tener en cuenta las diferencias entre las preferencias de los gobiernos subnacionales en materia de gastos. Amagoh y Amin (2012) llegaron a la conclusión de que, si bien la descentralización fiscal podría traer beneficios, su repercusión sobre el crecimiento estaba limitada por una serie de factores que dependían del contexto de las sociedades en cuestión. Baskaran y Feld (2013) también estudiaron un conjunto de países de la OCDE y hallaron que, cuando se usaban indicadores estándar del tipo de los que se emplean en las estadísticas de las finanzas públicas para representar de forma indirecta la descentralización fiscal, esta al parecer tenía un efecto negativo sin significancia estadística en el crecimiento. No obstante, hallaron que dicho efecto era estadísticamente significativo cuando se usaban nuevos indicadores que reflejaban el grado de autonomía fiscal subnacional. Gemmell, Kneller y Sanz (2013) estudiaron un conjunto de países de la OCDE y hallaron que la descentralización de los gastos solía estar asociada con un menor crecimiento económico, mientras que la descentralización de los ingresos solía asociarse con mayor crecimiento. Blöchliger (2013) halló que la descentralización fiscal se asociaba de manera positiva con el producto interno bruto (PIB) per cápita de algunos países de la OCDE, y que la descentralización de los ingresos tenía un efecto mayor que la descentralización de los gastos. Entre los trabajos representativos de países individuales se encuentran el de Xie, Zou y Davoodi (1999), sobre los Estados Unidos, el de Yifu Lin y Liu (2000), sobre China, y el de Rao (2000), sobre la India.

En lo que respecta a la estabilidad económica y la forma en que la descentralización fiscal la afecta, hay varios trabajos representativos: el de Neyapti (2004), en el que se toma un conjunto de países con distintos niveles de inflación y se llega a la conclusión de que, en los países donde la tasa de inflación es más elevada, la descentralización de los ingresos repercute negativamente en ella si dicha descentralización va acompañada por independencia del banco central y rendición de cuentas a nivel local, mientras que, en los países donde la inflación es más baja, los efectos negativos sobre ella siguen estando presentes sin necesidad de que haya factores adicionales; el de Neyapti (2010), en el que se analiza el tema de la disciplina fiscal y se concluye que, en un conjunto de 16 países, la descentralización de los gastos y los ingresos reduce el déficit presupuestario; el de Rodden, Eskeland y Litvack (2003), en el que se analiza la cuestión de cómo se mantiene la disciplina fiscal cuando los niveles inferiores de gobierno asumen responsabilidades que antes tenían las autoridades nacionales, y se examina de qué modo las restricciones presupuestarias "duras" y "blandas" afectan la estabilidad económica en países con distintos grados de desarrollo político e institucional, y el de Jalil, Harun y Che Mat (2012), que se centra en la estabilidad de los precios de 62 países y se concluye 
que la descentralización al parecer reduce la tasa de inflación en una medida que depende del grado de corrupción que hay en las instituciones políticas. Entre los estudios que se centran en países concretos se encuentran el de Bodman y otros (2009), sobre Australia, el de lqbal y Nawaz (2010), sobre el Pakistán, y el de Okonkwo y Godslove (2015), sobre Nigeria.

En cuanto a la descentralización fiscal, la pobreza y la distribución del ingreso, hay aportes importantes, como los siguientes: el de Boex y otros (2006), en el que además de ofrecer un análisis exhaustivo de la literatura sobre el tema, se brinda un conjunto de sugerencias cualitativas sobre cómo reformar en materia de descentralización desde una perspectiva que favorezca a los pobres; el de Sepúlveda y Martínez-Vázquez (2011), en el que se toma un gran conjunto de datos sobre países y se llega a la conclusión de que la descentralización fiscal al parecer reduce la pobreza, siempre y cuando la proporción del gasto subnacional no supere la tercera parte del total del gasto público, y que dicha descentralización al parecer también reduce la desigualdad de los ingresos, pero solo si el gobierno general representa una parte importante de la economía; el de Goerl y Seiferling (2014), en el que, sobre la base de un gran conjunto de datos sobre países, se halla que la descentralización del gasto público puede contribuir a lograr una distribución más equitativa de los ingresos, si se cumple una serie de condiciones, y el de Sacchi y Salotti (2014), en el que se examina un conjunto de países de la OCDE y se concluye que, a mayor grado de descentralización fiscal, mayor desigualdad de los ingresos entre los hogares. A nivel de los países individuales, cabe mencionar una muestra de estudios entre los que se encuentra el de Moon (2003), sobre Corea del Sur, el de Song (2013), sobre China, y el de Cavusoglu y Dincer (2015), sobre los Estados Unidos.

En una esfera de investigación reciente se analizan las repercusiones de la descentralización fiscal en lo que puede describirse como los derechos humanos fundamentales, expresión que abarca los derechos civiles y políticos, además de la libertad económica. Esta línea de investigación se ha explorado poco en economía, si bien no es nueva en otras esferas de las ciencias sociales, como se observa en la primera contribución de Kaufman (1969) y en un gran número de artículos subsiguientes, como el de Michels (2011) y el de Islam (2015). En economía, se destacan algunas excepciones, como la de Weingast (2009) y la de Bojanic (2016)

\section{Fundamentos teóricos de la relación entre la descentralización fiscal, el crecimiento, la inflación y la desigualdad de los ingresos}

El análisis de las investigaciones actuales sobre descentralización fiscal y su efecto sobre una serie de indicadores da la impresión de que no se sabe con certeza de qué manera la descentralización afecta algunas variables como el crecimiento, la estabilidad económica y la desigualdad de los ingresos. Sin embargo, el hecho de que la labor empírica en su estado actual no haya proporcionado una idea clara no ha impedido a los economistas formular hipótesis acerca de las formas en que cabría esperar que la descentralización afectara estas mismas variables. A continuación se brindará un breve resumen de los últimos trabajos teóricos y se procurará poner de relieve las cuestiones que probablemente sean importantes para comprender la forma en que la descentralización fiscal afecta el crecimiento, la estabilidad de los precios y la distribución del ingreso en América.

En lo que respecta al efecto que la descentralización fiscal podría tener sobre el crecimiento, ya hay numerosos estudios teóricos sobre el tema (véase, por ejemplo, Oates, 1993; Brueckner, 2005; Martínez-Vázquez y McNab, 2006). Al parecer, la respuesta depende de si una autoridad central está en mejores condiciones de utilizar la política fiscal para lograr un crecimiento a largo plazo, o si una estructura descentralizada dedicada a administrar los fondos públicos tiene mayor capacidad para 
lograr resultados que se traduzcan en crecimiento. Si bien la mayoría de los investigadores parece coincidir en que cabe esperar una correlación positiva entre el crecimiento y la descentralización, debido a que en los regímenes descentralizados se da un mejor destino a la infraestructura que propicia el crecimiento y hay más incentivos para ahorrar, la condicionante importante es que el contexto político e institucional del país donde tiene lugar la descentralización desempeña un papel. La conclusión es que, si bien es de esperar que haya una correlación positiva entre la descentralización fiscal y el crecimiento económico, el estado de desarrollo de la economía determinará si es posible traducir el proceso de descentralización en políticas que promuevan el crecimiento en el correr del tiempo.

En cuanto a los efectos que la descentralización fiscal tiene en la inflación, Martínez-Vázquez y McNab (2006) y Treisman (2000), entre otros, han elaborado un marco teórico sobre la forma en que es probable que la descentralización afecte la estabilidad de los precios. Sin formular hipótesis acerca de la dirección específica en que es probable que la descentralización afecte la estabilidad de los precios, su labor empírica en general muestra que, sobre todo en las economías desarrolladas, la correlación entre la inflación y la descentralización fiscal es inversa. Esto significa que, en los países con regímenes más descentralizados, es más probable que haya un menor nivel de inflación, mientras que, en las economías menos desarrolladas, parece ocurrir lo contrario y en realidad la descentralización puede producir un aumento de la inflación. Desde la perspectiva de los países de América, una consideración importante es que el gasto público descontrolado es uno de los principales motivos por los que en esos países se han observado tasas de inflación muy elevadas en el correr del tiempo, y que una gran proporción de dicho gasto ocurre en los niveles inferiores de gobierno. Esto pone de relieve la fundada preocupación por el hecho de que devolver esta función particular a los niveles subnacionales de gobierno puede dar lugar una vez más a presiones inflacionarias.

La labor teórica sobre la forma en que la descentralización fiscal afecta la distribución del ingreso no está tan desarrollada como la que se refiere al crecimiento y la estabilidad económica. Una excepción importante es el trabajo de Beramendi (2003), en el que se ofrece un modelo teórico para analizar la forma en que la descentralización interactúa con las políticas de redistribución y desigualdad, y se sostiene que la descentralización en sí misma no conduce necesariamente a niveles superiores (o inferiores) de desigualdad de los ingresos, sino que más bien la desigualdad depende en gran medida de las estructuras sociales y políticas internas de las regiones. Los estudios empíricos son más numerosos y entre ellos se encuentran, entre otros, el de Durham (1999), el de Sepúlveda y Martínez-Vázquez (2011) y, más recientemente, el de Goerl y Seiferling (2014). Desde la perspectiva de este artículo, si el crecimiento se considera una condición necesaria pero no suficiente para que aumente la igualdad de los ingresos, como lo propone Kuznets (1955), entonces la descentralización fiscal, en la medida en que cabe esperar que tenga efectos positivos en el crecimiento, también debería contribuir, en última instancia, a que los ingresos fueran más igualitarios.

Junto con las conclusiones teóricas y empíricas que se acaban de describir, hay otros dos factores importantes que se deben tener en cuenta al examinar la descentralización en los países en desarrollo de América: la limitada capacidad institucional de los niveles subnacionales de gobierno para recaudar sus propios ingresos, y las disparidades económicas, políticas y culturales muy reales que existen dentro de los países y entre ellos.

La incapacidad de los gobiernos subnacionales para recaudar sus propios ingresos hace que dependan de las transferencias del gobierno central. Esta situación crea ineficiencias, dado que esas transferencias pueden no ser automáticas y estar ligadas a cálculos políticos. Las disparidades regionales dentro de los países y entre ellos significan que la descentralización en los países en desarrollo de América ha tenido lugar en entornos muy heterogéneos, y, por lo tanto, no debería sorprender que el grado de descentralización varíe no solo entre los países sino también entre las regiones de cada país. La desigualdad de los ingresos, el grado de urbanización, los 
desequilibrios territoriales y las tasas de alfabetización son solo algunos de los factores que pueden afectar la forma en que el proceso de descentralización se consolida en un entorno particular. La cuestión es que, en el contexto de la descentralización en esta parte del mundo, las disparidades regionales y el hecho de que los gobiernos subnacionales dependan del gobierno central para recaudar impuestos probablemente desempeñen un papel importante en la eficacia y la utilidad de la descentralización fiscal.

\section{Datos y metodología}

Una de las dificultades más grandes que supone estudiar la descentralización fiscal en varios países es medir correctamente el alcance de la descentralización en varios niveles de gobierno. Un problema relacionado cuando el estudio se centra sobre todo en países en desarrollo es la dificultad para hallar datos fiables y creíbles. Un escenario óptimo sería aquel en que el conjunto de datos que se construyera fuera plenamente comparable entre los países y reflejara en verdad las decisiones autónomas de los gobiernos subnacionales. Como cabría esperar, construir ese conjunto de datos es una tarea muy ardua, sobre todo porque requiere conocer el grado de autonomía de los gobiernos subnacionales en lo que respecta a la recaudación de ingresos y a las decisiones en materia de gastos. También exige un conocimiento profundo del sistema tributario de cada país y, en particular, de la estructura de participación de las regiones en los ingresos, la naturaleza de las subvenciones y las transferencias entre el gobierno central y los niveles subnacionales de gobierno, y el nivel general de autonomía política regional. Habida cuenta de lo difícil que es hallar indicadores de descentralización que permitan determinar todo lo anterior, la práctica habitual en la literatura sobre economía ha consistido en utilizar los datos que el Fondo Monetario Internacional (FMI) reúne y presenta en su Government Finance Statistics Yearbook (GFSY) como principal fuente de datos sobre ingresos y gastos a nivel nacional (general) y subnacional de gobierno ${ }^{3}$. Aunque en el GFSY no se brinda información sobre la naturaleza de las transferencias gubernamentales, no se indica si las transferencias y los subsidios están bajo el control del nivel nacional o del subnacional y, de hecho, en la actualidad no se ofrecen datos desglosados en relación con muchos países en desarrollo, dicha publicación también es la principal fuente de datos del presente estudio. Sin embargo, no es la única. Además de la información que brinda el GFSY, se han usado datos sobre descentralización de los ingresos de la OCDE Comisión Económica para América Latina y el Caribe (CEPAL) $)^{5}$, en los casos en que fue posible, de los institutos nacionales de estadística o instituciones estatales similares de cada país 6 .

La medida estándar de descentralización fiscal que se utiliza en la mayoría de los estudios sobre este tema es la razón entre el total de los ingresos públicos subnacionales y los ingresos públicos generales, así como la razón entre el total del gasto público subnacional y el general. Estos dos indicadores de descentralización fiscal también se utilizan aquí. Los datos nacionales y los del GFSY, la OCDE y la CEPAL proporcionan información a nivel del gobierno general consolidado y, en algunos países, a escala de los gobiernos regionales, estatales y locales. Los ingresos (los gastos) en los planos subnacionales de gobierno (regional, estatal y local) se sumaron para obtener una sola cifra correspondiente a los ingresos (los gastos) del gobierno subnacional. De los 23 países de América

3 Véase [en línea] http://www.imf.org/external/pubs/ft/gfs/manual/comp.htm.

4 Véase [en línea] www.oecd.org/ctp/federalism/fiscal-decentralisation-database.htm.

5 Véase [en línea] estadisticas.cepal.org/cepalstat/WEB_CEPALSTAT/Portada.asp.

6 Los datos sobre descentralización del Estado Plurinacional de Bolivia son fáciles de obtener en el Instituto Nacional de Estadística del país (www.ine.gob.bo). Del mismo modo, los datos sobre la Argentina pueden obtenerse de la Comisión Federal de Impuestos (www.cfi.gov.ar) y del Ministerio de Hacienda y Finanzas Públicas (www.economia.gob.ar). En cuanto al resto de los países en desarrollo de América a los que se refiere este estudio, fue más difícil obtener datos sobre descentralización de una entidad pública nacional, por lo que se utilizaron los datos que se brindan en el GFSY, la OCDE o la CEPAL. 
(con exclusión del Caribe), hay 12 en relación con los cuales se cuenta con datos desglosados entre el nivel general y subnacional de gobierno. Por consiguiente, el presente estudio se centra en esa submuestra respecto de la cual se dispone de datos ${ }^{7}$. Las observaciones anuales van de 1972 a 2015, aunque las fechas de los datos disponibles de los 12 países no siempre coinciden. El número de observaciones oscila entre un mínimo de 91 y un máximo de 208, según los siguientes factores: i) el hecho de si los indicadores de descentralización que se utilizan como regresores son los que corresponden a los ingresos o a los gastos; ii) el método particular que se utiliza para calcular la regresión, y iii) la variable dependiente del modelo (el crecimiento del PIB per cápita, la tasa de inflación o el coeficiente de Gini). El resultado final es un conjunto de datos de panel no equilibrado que tiene un máximo de 208 observaciones correspondientes a 12 países de América, que abarcan de 1972 a 2015. Si bien en el conjunto de datos hay algunas lagunas considerables, se decidió no utilizar promedios ni aproximaciones lineales para subsanarlas, sino dejar que el conjunto de datos real hablara por sí mismo.

Las tres variables dependientes que se utilizaron aquí son el crecimiento del PIB per cápita, la tasa de inflación y el coeficiente de Gini ${ }^{8}$. Las variables de control correspondientes al conjunto de regresiones relativas a la descentralización fiscal y el crecimiento económico son las siguientes: la tasa de inflación (expresada como porcentaje); el ahorro interno bruto (porcentaje del PIB) como indicador indirecto de la formación de capital; la apertura al comercio internacional, es decir, (exportaciones + importaciones)/PIB, expresada como porcentaje; las remesas (porcentaje del PIB); la inversión extranjera directa (IED) (porcentaje del PIB); la tasa de desempleo (porcentaje); el gasto de consumo final del gobierno general (porcentaje del PIB) como indicador indirecto del tamaño del gobierno; la población urbana (porcentaje), y un índice de libertades políticas y civiles como medida de la estabilidad política y los derechos fundamentales ${ }^{9}$. Cuando la tasa de inflación se usa como variable dependiente, las variables de control son el PIB per cápita en niveles (en paridad del poder adquisitivo, en logaritmos), la apertura al comercio internacional, el gasto de consumo final del gobierno general, el gasto militar (como porcentaje del PIB), la IED y las remesas. Por último, cuando la variable dependiente es el coeficiente de Gini, las variables de control son las siguientes: el PIB per cápita en niveles y el PIB per cápita al cuadrado, para tener en cuenta la hipótesis de Kuznets (1955) de que el crecimiento de los ingresos per cápita al principio aumenta la desigualdad, pero, en última instancia, la reduce; la población urbana; la apertura al comercio internacional; un índice de las libertades políticas y civiles, en procura de captar la medida en que los derechos humanos fundamentales afectan la desigualdad; las remesas; el ahorro interno bruto; el gasto de consumo final del gobierno general; la tasa de inflación; los usuarios de Internet (cada 100 personas), y la tasa de desempleo ${ }^{10}$.

En cada caso, las especificaciones particulares se ajustan a las investigaciones anteriores sobre temas similares, pero se incluyeron variables de control adicionales cuando se consideró pertinente, a saber: las remesas y un índice de libertades políticas y civiles, cuando la variable dependiente es el crecimiento económico; las remesas, cuando dicha variable es la tasa de inflación, y un índice de libertades políticas y civiles, los usuarios de Internet y la tasa de desempleo, cuando la variable dependiente es el coeficiente de Gini.

\footnotetext{
7 Los 12 países que se incluyeron en el presente estudio son los siguientes: Argentina, Bolivia (Estado Plurinacional de), Brasil, Canadá, Chile, Colombia, Costa Rica, El Salvador, Estados Unidos, México, Paraguay y Perú.

8 Las cifras de crecimiento del PIB per cápita se calculan en paridad del poder adquisitivo.

9 Este índice combinado se obtiene de Freedom House, que compila índices independientes de los derechos políticos y las libertades civiles, y prepara evaluaciones cualitativas del grado de libertad en cada país. En este caso, se combinaron ambos índices y las evaluaciones cualitativas para obtener un único índice de libertades políticas y civiles que va desde 0,18 (el más libre) hasta 1,00 (el menos libre). Véase [en línea] http://freedomhouse.org/report-types/freedom-world\#.VY_fWl1RHcw.

${ }^{10}$ Con excepción de las libertades políticas y civiles, la fuente de todas las variables es el Banco Mundial. Véase [en línea] http:// data.worldbank.org/data-catalog/world-development-indicators.
} 
En lo que respecta a la especificación de los modelos, se usaron distintos métodos de regresión para tratar las limitaciones y las lagunas en materia de información dentro de un conjunto de datos de panel no equilibrado, la correlación probable de las observaciones dentro y entre las secciones, y la gran variabilidad de los datos correspondientes a los países de la muestra. En concreto, se calcularon regresiones con mínimos cuadráticos generalizados (MCG) y con variables instrumentales para tomar en cuenta la heterocedasticidad y la autocorrelación entre las secciones y dentro de ellas ${ }^{11}$, y también se calcularon MCG con efectos fijos y aleatorios entre las secciones para tener en cuenta, respectivamente, el sesgo debido a las variables omitidas y los efectos de las variables que no varían en el tiempo. Además, se calcularon regresiones con el método generalizado de momentos (MGM) para reflejar el carácter dinámico de la relación entre la descentralización fiscal, el crecimiento, la inflación y la desigualdad de los ingresos ${ }^{12}$.

\section{Resultados del análisis empírico}

Como introducción al análisis empírico, en el cuadro 1 se ofrecen estadísticas resumidas correspondientes a los 12 países de América que se analizan en este estudio y se indica el período que abarca cada indicador de descentralización.

Las estadísticas resumidas demuestran que existe una gran variación entre los países de América en cuanto al grado de descentralización fiscal. De todos los países analizados, el Canadá es el más descentralizado: tanto el indicador del ingreso como el del gasto superan con creces el $70 \%$ en promedio ${ }^{13}$. Costa Rica, El Salvador y el Paraguay están en el otro extremo del espectro, ya que el promedio de los ingresos y los gastos descentralizados es de un solo dígito ${ }^{14}$. Entre esos dos extremos, el grado de descentralización fiscal en el resto de los países no es homogéneo. En países como el Brasil y los Estados Unidos se observa un grado de descentralización importante (los indicadores de descentralización de los ingresos y los gastos se sitúan en alrededor del 50\%), si bien este no se acerca al del Canadá. En cuanto a los demás países, la Argentina y Colombia parecen inclinarse hacia una mayor descentralización, ya que el promedio de los indicadores porcentuales de los ingresos y los gastos es de alrededor del 40\%. En México, el Perú y el Estado Plurinacional de Bolivia, por otra parte, el promedio de los dos indicadores alcanza valores intermedios dentro de la muestra y se sitúa en alrededor del $30 \%{ }^{15}$. Chile se inclina hacia un nivel más bajo de descentralización: en lo que respecta a los ingresos, esta es de un solo dígito cercano al 10\% y, en lo que se refiere a los gastos, supera por un poco dicha cifra. Cabe señalar también que, si bien los datos brutos parecen sugerir que el grado de descentralización de la mayoría de los países aumenta con el tiempo, esto no siempre es cierto, como queda demostrado en el caso de los Estados Unidos, donde los indicadores de descentralización de los ingresos y los gastos parecen mostrar una tendencia descendente en el tiempo.

\footnotetext{
${ }^{11}$ En el caso de las regresiones con MCG y con variables instrumentales, se calculó el estimador de efectos fijos de Prais-Winsten de errores estándar corregidos para panel, a fin de corregir la correlación serial (la correlación de corte transversal y entre períodos).

12 Las regresiones correspondientes al MGM se calcularon usando el método de los errores estándar corregidos para panel a fin de tener en cuenta la correlación de corte transversal y entre períodos.

${ }^{13}$ Como se definió en la sección IV, el indicador de descentralización del ingreso (o el gasto) es la razón entre el ingreso (o el gasto) de los gobiernos subnacionales y el ingreso (o el gasto) del gobierno general.

14 En El Salvador, el bajo grado de descentralización solo se refiere a los ingresos.

${ }^{15}$ En México, el grado de descentralización de los gastos es bastante elevado, con un promedio de alrededor del 45\% en el período de 1990 a 2013. En cuanto a los ingresos, el promedio del indicador es de solo el 30\%, aproximadamente, pero esto puede ser consecuencia de que el período es más largo (de 1972 a 2013).
} 


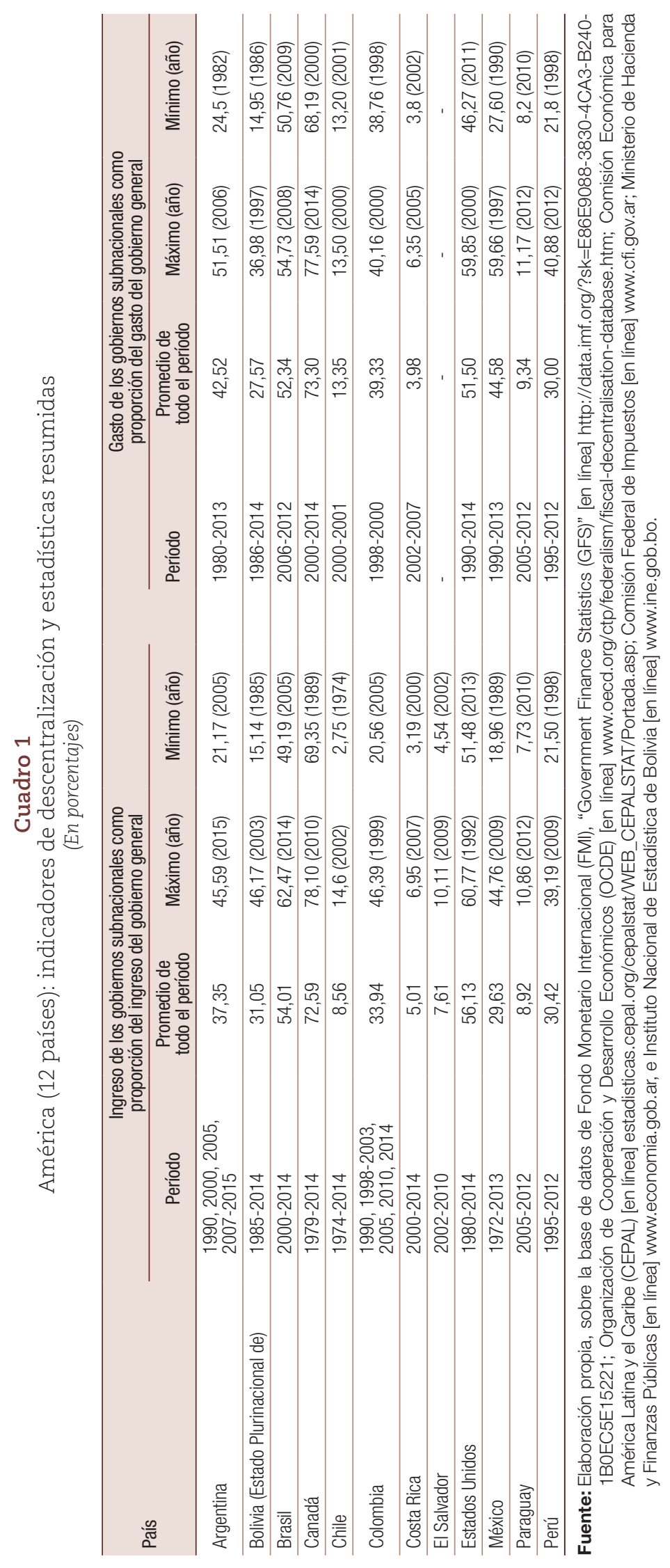


Los resultados de las regresiones que muestran el efecto de la descentralización fiscal en el PIB per cápita, la inflación y el coeficiente de Gini se proporcionan en dos grupos: en el primero se incluyen los 12 países, y en el segundo se excluyen el Canadá y los Estados Unidos, los dos países que probablemente tienen los sistemas de descentralización más desarrollados y estables del hemisferio. Excluir estos dos países ofrece la ventaja de mostrar la situación de la descentralización fiscal solo desde la perspectiva de los países en desarrollo de América.

En primer lugar se analiza el efecto de la descentralización fiscal sobre el crecimiento. En el cuadro 2 se presentan los resultados de las regresiones cuando se consideran los 12 países y la variable dependiente es el crecimiento del PIB per cápita.

En las cinco columnas del cuadro 2 se muestran las estimaciones correspondientes a los cinco métodos que se describen en la sección IV. En la primera, se presenta un modelo de MCG que refleja la autocorrelación y la heterocedasticidad entre las secciones y dentro de ellas. En la segunda y la tercera columna se presentan modelos de MCG con efectos fijos y aleatorios de corte transversal. En la cuarta y la quinta columna aparecen estimaciones que corresponden a cuando se utilizan variables instrumentales y cuando se usa el MGM. Las especificaciones de las variables instrumentales y el MGM se estimaron teniendo en cuenta la autocorrelación y la heterocedasticidad entre las secciones y dentro de ellas. Además, en cada columna figuran los resultados de dos regresiones: la primera muestra las estimaciones que corresponden a cuando el indicador de la descentralización fiscal se refiere a los ingresos, y la segunda muestra las que corresponden a cuando este se refiere a los gastos.

Como se desprende de los resultados que se señalan, el indicador de descentralización fiscal referido a los ingresos muestra de forma sistemática un efecto negativo en el crecimiento económico. En todas las especificaciones, salvo en la de los MCG con efectos fijos, los coeficientes de esta variable son negativos, tienen más o menos el mismo tamaño y son estadísticamente significativos en todos los casos. En lo que respecta a los gastos, la variable correspondiente a la descentralización fiscal es positiva en su mayoría, pero solo es estadísticamente significativa cuando se la calcula con el MGM, lo que está en consonancia con los supuestos que se formularon en la sección III, en particular el que se refiere a que los gastos descentralizados tienen más probabilidades de destinarse a proyectos de inversión que propicien el crecimiento ${ }^{16}$. En su conjunto, sin embargo, los datos empíricos no apoyan de manera concluyente la hipótesis de que la descentralización promueve el crecimiento, en particular en lo que respecta a la descentralización de los ingresos.

\footnotetext{
${ }^{16}$ Cuando en la especificación se emplean variables instrumentales, se halla que la variable correspondiente a la descentralización de los gastos es negativa y estadísticamente significativa al 10\%, lo que pone de relieve la debilidad de los datos estadísticos que se hallan en este estudio como justificación de los efectos positivos que se espera que la descentralización fiscal tenga en el crecimiento económico.
} 


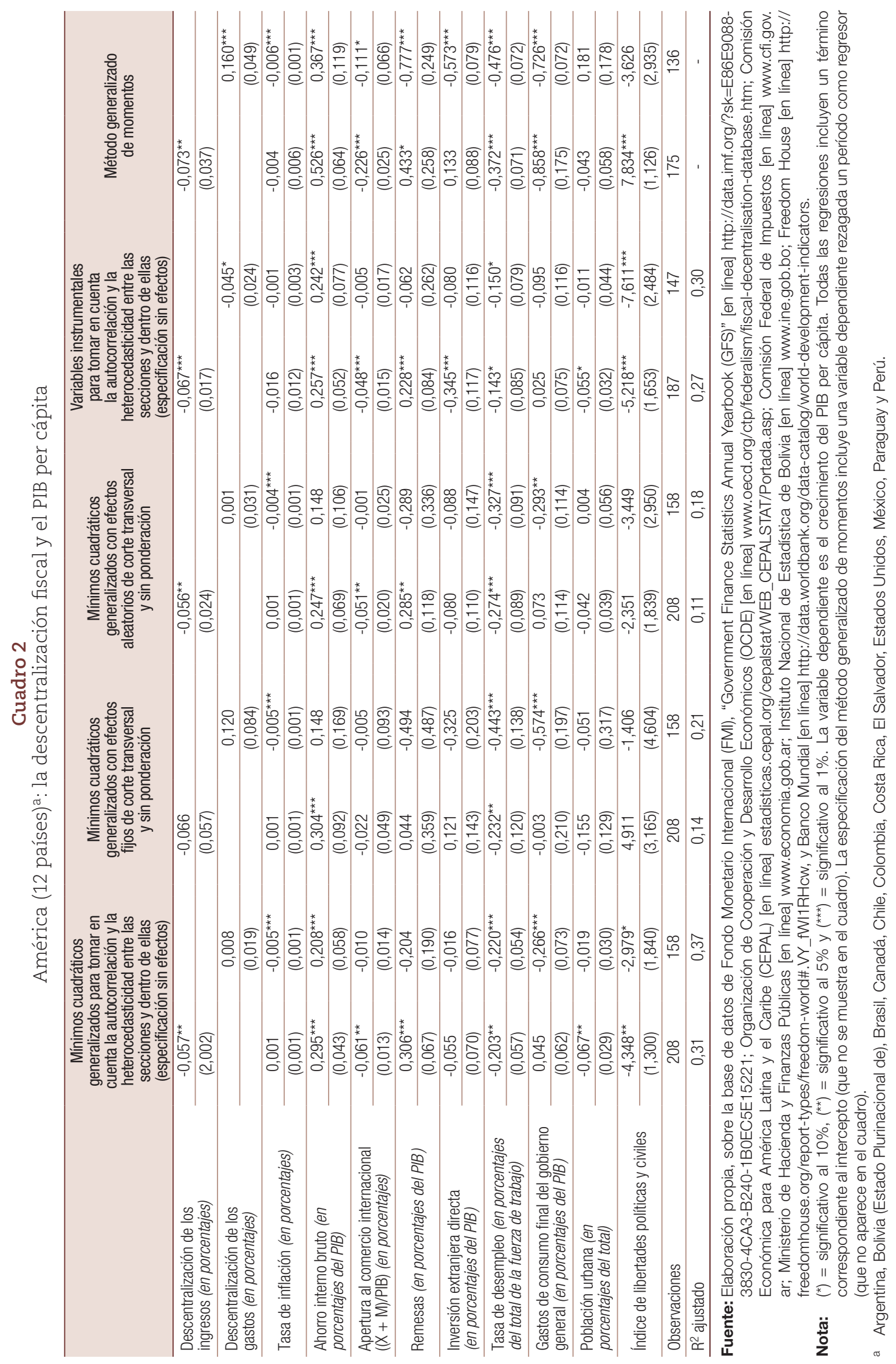


El comportamiento de las variables de control también es digno de mención. Los resultados correspondientes a la mayoría de ellas se ajustan a las expectativas acerca de sus probables efectos en el crecimiento. Por ejemplo, el ahorro tiene el efecto positivo previsto en la variable dependiente, sin importar qué especificación se utilice; la tasa de desempleo, por su parte, muestra el impacto negativo que cabe esperar que tenga en el crecimiento. También se muestra que la apertura al comercio internacional no propicia el crecimiento, lo que concuerda con un segmento considerable de la literatura sobre economía en el que se expresan reservas respecto al efecto del comercio ${ }^{17}$. Se obtiene un resultado similar en relación con la IED, ya que el emparejamiento de las estimaciones correspondientes a la variables instrumentales y el MGM con los indicadores de ingresos y gastos de la descentralización fiscal muestra que la IED tiene un efecto muy negativo y significativo en el crecimiento, lo que pone de relieve la preocupación por los efectos de la inversión extranjera en este sentido. Como cabría esperar, el efecto de las remesas es positivo y significativo en su mayoría, pero esta variable puede tener el efecto contrario al analizarla desde una perspectiva dinámica. El aumento de la inflación y del tamaño del gobierno (medido según la variable relativa al gasto de consumo final del gobierno general), así como la mayor urbanización, también parecen conducir a una disminución del crecimiento. Por último, el aumento de las libertades políticas y civiles al parecer propicia un mayor crecimiento, aunque es posible que esta variable (el índice de libertades políticas y civiles) tenga un efecto más matizado en un entorno dinámico ${ }^{18}$.

En el cuadro 3 se presentan los resultados de las regresiones que muestran cómo la descentralización fiscal afecta el crecimiento cuando el Canadá y los Estados Unidos se excluyen del análisis. Las especificaciones y las propiedades estadísticas de cada regresión son las mismas que en el cuadro 2.

Como ocurría con la muestra completa de países, en lo que respecta a los ingresos, la descentralización fiscal exhibe de forma sistemática un efecto perjudicial en el crecimiento. Los coeficientes de esta variable son negativos en su mayoría y son estadísticamente significativos cuando se los calcula utilizando MCG (sin efectos y con efectos aleatorios) y variables instrumentales. En cuanto a los gastos, los coeficientes del indicador de descentralización son positivos en todos los casos y son estadísticamente significativos cuando se los calcula utilizando MCG (con efectos fijos) y el MGM, lo que demuestra que la descentralización de los gastos parece desempeñar un papel importante como promotora de crecimiento económico en los países en desarrollo de América. Este resultado es más concluyente que el que se había observado con la muestra completa de países y pone de manifiesto que, para este conjunto de países en desarrollo de América, la descentralización de los gastos sí puede tener el efecto positivo previsto en el crecimiento.

Con respecto a las variables de control, su conducta se asemeja en general a la que se observaba con la muestra completa de países. El ahorro y la tasa de desempleo exhiben de forma constante el efecto positivo y negativo, respectivamente, que se espera que tengan en el crecimiento, mientras que la apertura al comercio, la IED y el mayor tamaño del gobierno muestran un efecto negativo semejante en el crecimiento. Las remesas también parecen tener un efecto positivo en el crecimiento, pero, como ocurría con la muestra completa de países, el efecto de esta variable en un entorno dinámico podría ser más matizado. También se muestra que la inflación tiene una incidencia negativa en el crecimiento en la mayoría de los casos, al tiempo que, a diferencia de lo que ocurre cuando los casos del Canadá y los Estados Unidos se incluyen en el análisis, el grado de urbanización no parece desempeñar ningún papel en el crecimiento. Por último, el aumento de las libertades políticas y civiles parece fomentar el crecimiento económico, aunque, una vez más, el efecto de esta variable en un marco dinámico parece tener más matices.

\footnotetext{
${ }^{17}$ En Rodríguez y Rodrik (1999) se proporciona un buen informe de resultados en el que se abordan algunas de las reservas sobre los efectos del comercio en el crecimiento.

${ }^{18}$ El índice de libertades políticas y civiles va de 0,18 (el más libre) a 1,00 (el menos libre).
} 


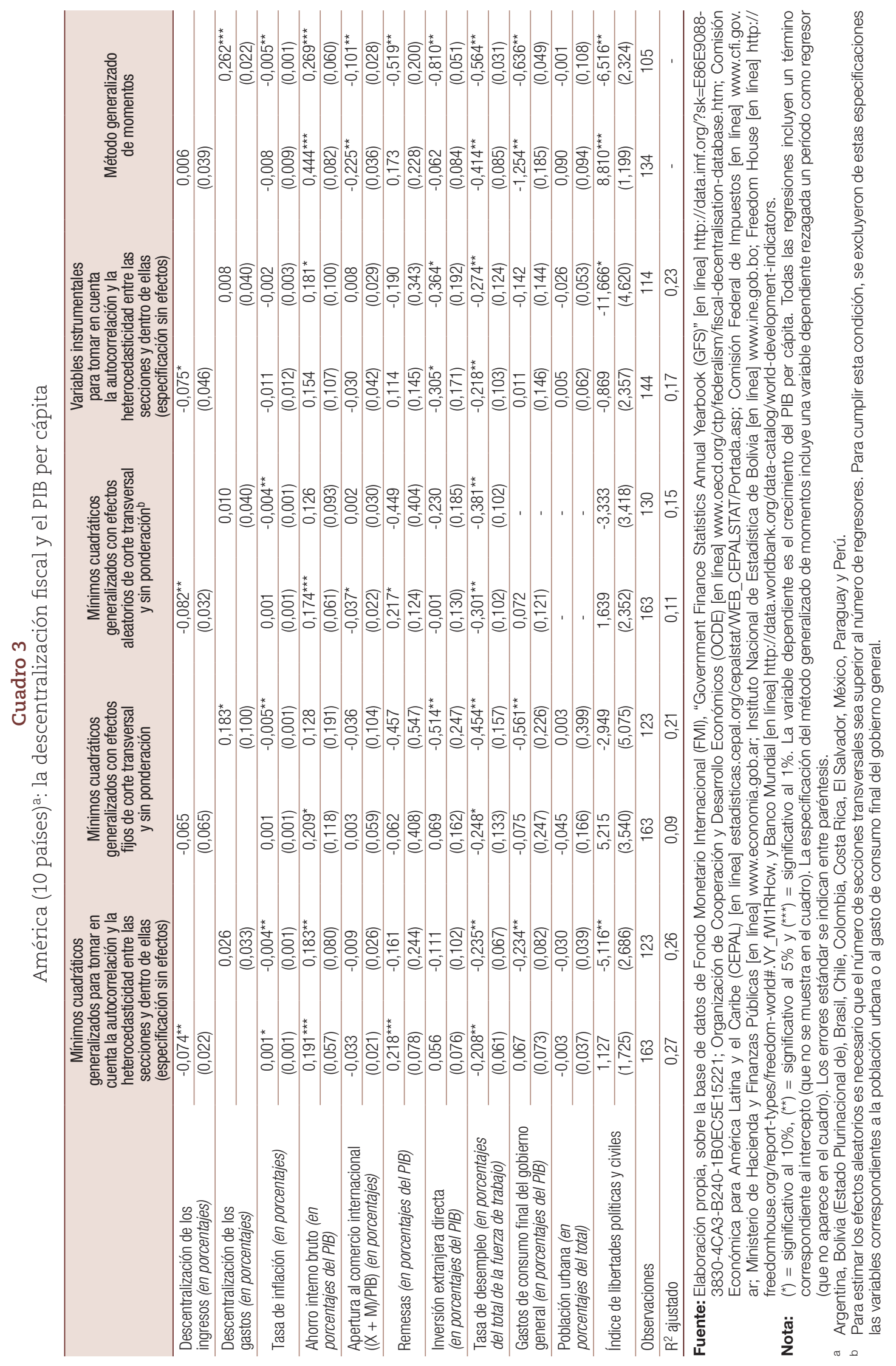


En los cuadros 4 y 5 se analiza cómo incide la descentralización fiscal en la tasa de inflación. Los métodos de regresión son los mismos que se utilizaron cuando la variable dependiente era el crecimiento. En el cuadro 4 se presentan los resultados de las estimaciones realizadas en relación con todos los países analizados.

Los resultados correspondientes a los efectos de las variables de descentralización fiscal sobre la tasa de inflación no son concluyentes. Cuando hay descentralización de los ingresos, las estimaciones relativas al indicador de descentralización en las que se utilizan los MCG son positivas y estadísticamente significativas, lo que sugiere que la mayor descentralización propicia un aumento de la inflación. Sin embargo, cuando en la especificación se emplean variables instrumentales y la relación se analiza en un entorno dinámico, los efectos de la descentralización de los ingresos se invierten, lo que significa que esta en realidad modera la inflación. En el caso del indicador de descentralización de los gastos, los resultados son un poco más claros: las estimaciones hechas con MCG y variables instrumentales muestran una correlación positiva y estadísticamente significativa entre la descentralización de los gastos y la inflación, pero la relación se invierte cuando la estimación se hace según el MGM, lo que sugiere que el modo en que la descentralización de los gastos repercute en la inflación no es del todo claro. La falta de claridad de los resultados impide llegar a conclusiones definitivas sobre el efecto que la descentralización fiscal tiene en la inflación y, por lo tanto, no se puede afirmar de forma inequívoca que esta desaliente o induzca la inflación en los países de América.

En cuanto a las variables de control, el crecimiento del PIB per cápita se asocia sistemáticamente con una menor inflación; este resultado no sorprende en vista de las conclusiones de algunos estudios anteriores, como el de Martínez-Vázquez y McNab (2006) ${ }^{19}$. El gasto público y la IED por lo general mitigan la inflación, mientras que los resultados correspondientes al resto de las variables (apertura al comercio internacional, gasto militar y remesas) no son concluyentes.

En el cuadro 5 se presentan los resultados correspondientes a los efectos de la descentralización fiscal sobre la tasa de inflación cuando el Canadá y los Estados Unidos se excluyen del análisis.

Como es evidente, los resultados confirman en gran medida los que se presentaron en el cuadro 4. Los dos indicadores de descentralización fiscal muestran la misma pauta de comportamiento que se observa con la muestra completa de países, de ahí la dificultad para extraer conclusiones definitivas. En determinadas condiciones, la descentralización de los ingresos parece fomentar la inflación, como se observa en las estimaciones positivas y estadísticamente significativas de los MCG; en otras condiciones, no obstante, ocurre lo contrario, como se observa cuando la especificación incluye variables instrumentales y cuando se emplea el MGM. Del mismo modo, la descentralización de los gastos parece favorecer más la inflación cuando los cálculos se hacen utilizando los MCG y las variables instrumentales, pero, en un contexto dinámico, el resultado es el opuesto. Como se había concluido en relación con toda la muestra de países, no se puede afirmar de forma inequívoca que la descentralización fiscal desaliente o induzca la inflación en los países en desarrollo de América.

El comportamiento de las variables de control queda un poco mejor definido con esta muestra de países. Como era de esperar, el PIB per cápita se asocia en la mayoría de los casos con una menor inflación, al igual que el gasto público y la IED, lo que demuestra que el tamaño del gobierno y las entradas netas de capital desempeñan un papel positivo en cuanto a prevenir la inflación²0. El gasto militar parece propiciar un aumento de la inflación, pero, cuando va acompañado de una descentralización de los ingresos, puede desalentarla. Por último, el efecto de la apertura al comercio y las remesas es indeterminado.

${ }^{19}$ El modelo de los MCG con efectos fijos de corte transversal invierte la tendencia general y muestra que el PIB per cápita tiene un efecto positivo y significativo en la inflación. Dado que las otras técnicas asociadas con los MCG, así como las variables instrumentales y el MGM, siempre dan lugar a coeficientes negativos y estadísticamente significativos en relación con esta variable, el resultado de los MCG con efectos fijos se considera una anomalía.

20 En un entorno dinámico, la IED puede propiciar un aumento de la inflación, como se pone de manifiesto en la especificación del MGM. Del mismo modo, el mayor tamaño del gobierno también puede tener un efecto positivo en la inflación, como queda reflejado en el cálculo en que se emplean variables instrumentales cuando la descentralización se produce en relación con los ingresos. 


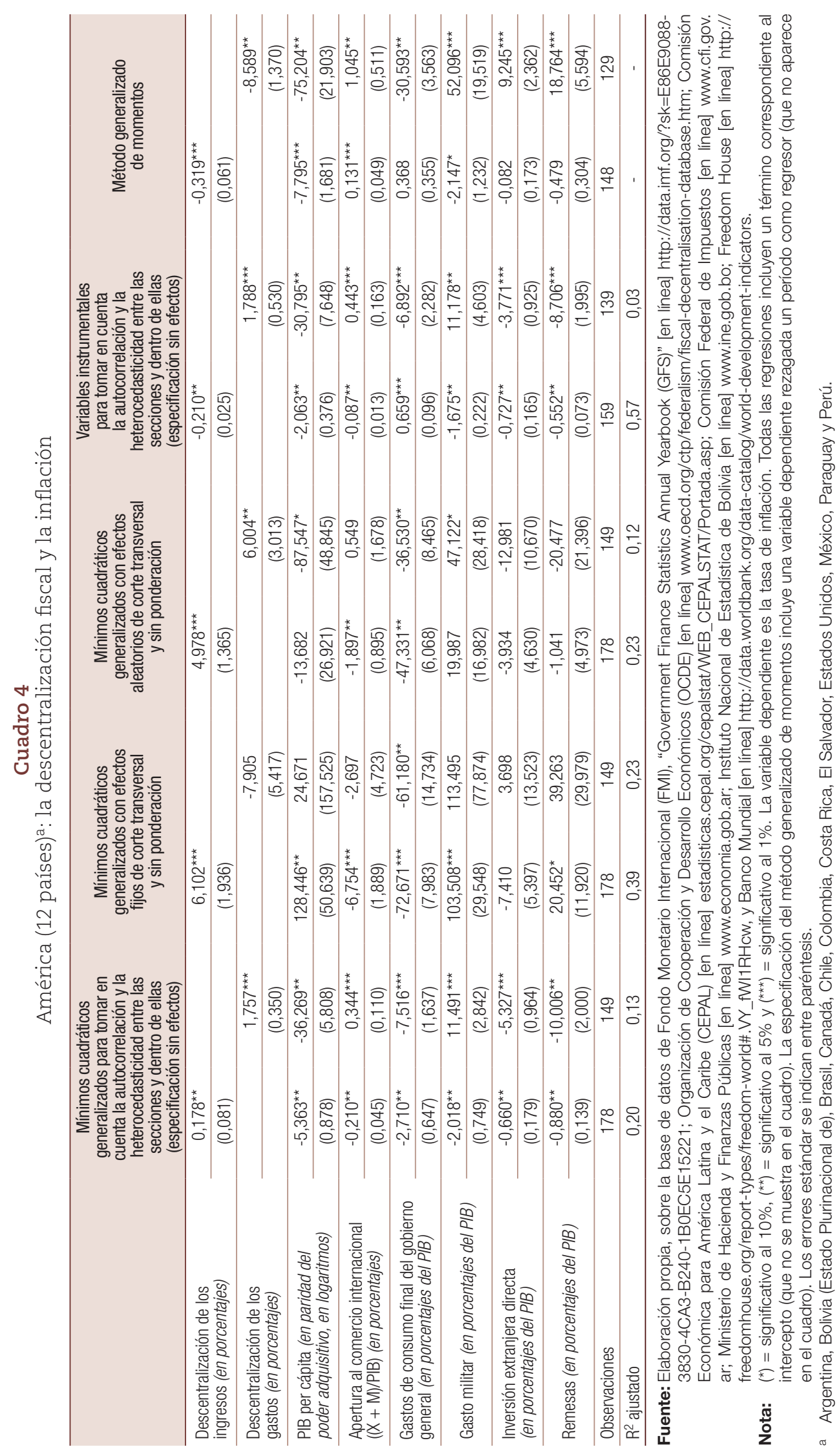




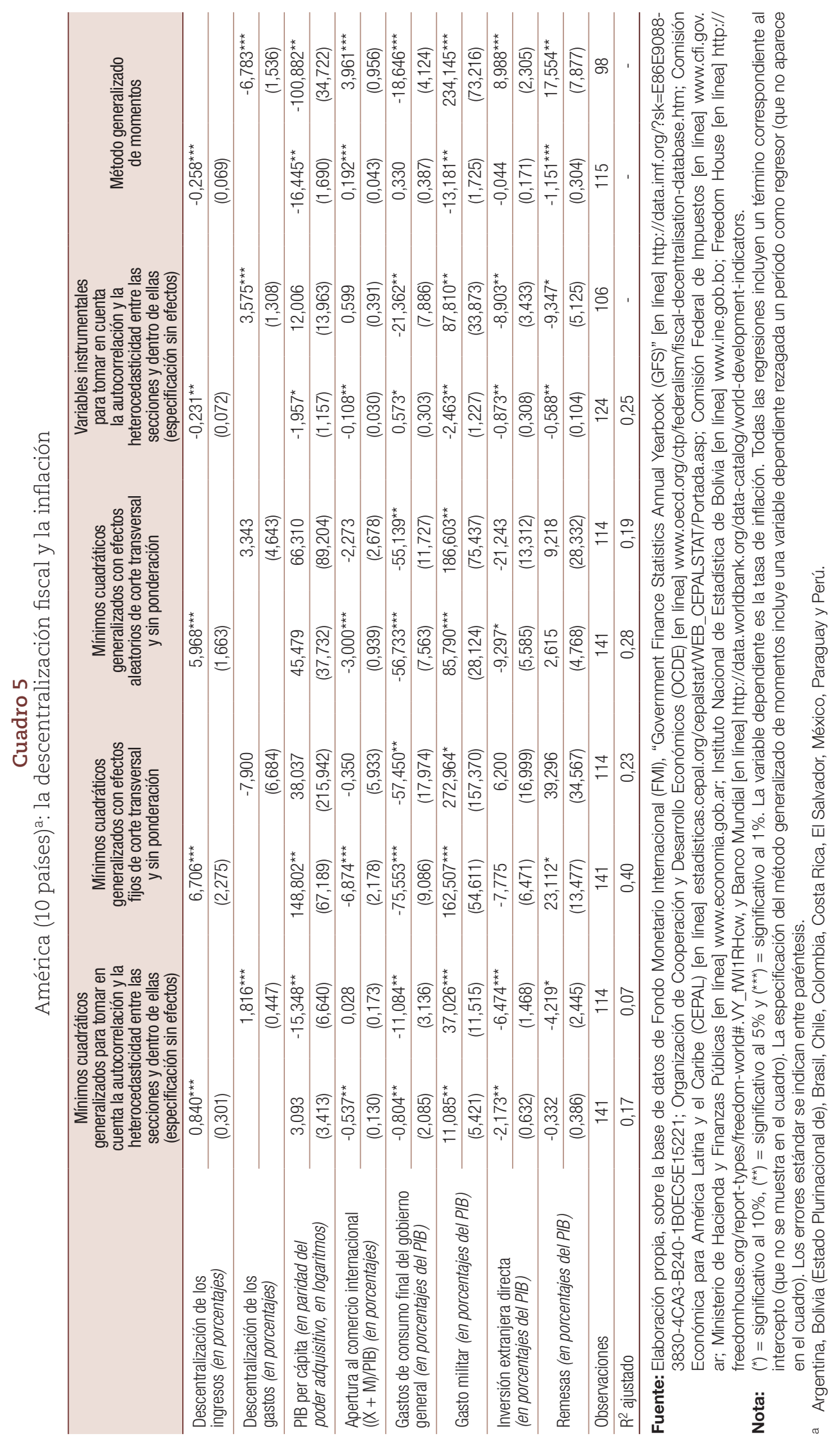


El último conjunto de regresiones figura en los cuadros 6 y 7. En el cuadro 6 se presentan los resultados relativos al efecto de la descentralización fiscal en el coeficiente de Gini en toda la muestra de países.

El efecto de la descentralización fiscal en el coeficiente de Gini varía según que esta ocurra en relación con los ingresos o con los gastos. Hay pruebas sustanciales de que la descentralización de los ingresos desempeña un papel positivo en la creación de condiciones que propicien una mayor igualdad, como queda de manifiesto en los coeficientes negativos, estadísticamente significativos y de tamaño más o menos similar que se obtienen en relación con el indicador de descentralización de los ingresos cuando se utilizan las especificaciones de los MCG sin efectos y con efectos aleatorios. La descentralización de los gastos, en cambio, no parece tener efectos, dado que, en todos los casos, los coeficientes estimados en relación con esta variable son cercanos a cero y no son estadísticamente significativos. Por consiguiente, la conclusión general es que la descentralización de los ingresos al parecer desempeña el papel positivo previsto en cuanto a crear condiciones que propicien una mayor igualdad de ingresos, mientras que la descentralización de los gastos parece ser ineficaz para resolver los problemas de desigualdad.

El comportamiento de las variables de control también es digno de mención. El PIB per cápita en niveles y el PIB per cápita al cuadrado no parecen tener una pauta clara de comportamiento y, por lo tanto, no es posible llegar a una conclusión definitiva sobre la manera en que esas variables afectan la desigualdad de los ingresos. La falta de uniformidad de la pauta de comportamiento de la variable correspondiente al PIB indica, sin embargo, que las hipótesis de Kuznets, según la cual habría una mayor desigualdad en las etapas iniciales de desarrollo, pero menos desigualdad en las etapas más avanzadas, tal vez no se aplique en este caso. Hay pruebas convincentes de que el aumento de la urbanización, la apertura al comercio internacional, el mayor tamaño del gobierno y el incremento del desempleo agravan la desigualdad de los ingresos, como se refleja en los coeficientes correspondientes a esas variables, que de forma sistemática son positivos y estadísticamente significativos. Estos resultados están en perfecta consonancia con las conclusiones de otros estudios (véase, por ejemplo, Rodríguez y Rodrik, 1999; Lee, 2005; Martínez, Ayala y Ruiz-Huerta, 2001), según las cuales la urbanización, la apertura de los mercados, el aumento de la actividad del gobierno y el mayor desempleo son los principales impulsores de la desigualdad de los ingresos. El ahorro y las remesas, por otra parte, parecen favorecer una mayor igualdad de los ingresos, lo que se observa en los coeficientes que, de forma constante, son negativos y estadísticamente significativos. Este resultado tampoco sorprende, dada la importancia que la postergación del consumo y las fuentes alternativas de ingresos tienen como instrumentos para reprimir la desigualdad de estos. Al parecer, la inflación también disipa la desigualdad, como lo indican las estimaciones negativas y estadísticamente significativas que se obtienen en relación con esta variable al emplear distintas técnicas. Este resultado coincide con las conclusiones de otros estudios (p. ej., Monnin, 2014), según las cuales las políticas monetarias destinadas a controlar la inflación han actuado en detrimento de la población que pertenece a los grupos de ingresos medios e inferiores y, por lo tanto, han aumentado la desigualdad de los ingresos. El argumento es que, cuando los salarios se aceleran y los bancos centrales ajustan la política monetaria, el desempleo aumenta, lo que supone un empeoramiento de la desigualdad de los ingresos. El argumento contrario es que, entonces, una mayor inflación puede reducir la desigualdad de los ingresos al permitir que los salarios crezcan más. Por último, los índices relacionados con las libertades políticas y civiles y los usuarios de Internet no siguen una pauta que se pueda discernir, por lo que no es posible sacar conclusiones sobre sus efectos en la desigualdad de los ingresos.

En el cuadro 7 se muestran las estimaciones que se obtuvieron al hacer regresiones sobre el efecto de la descentralización fiscal en el coeficiente de Gini en los países de América, con exclusión del Canadá y los Estados Unidos. 


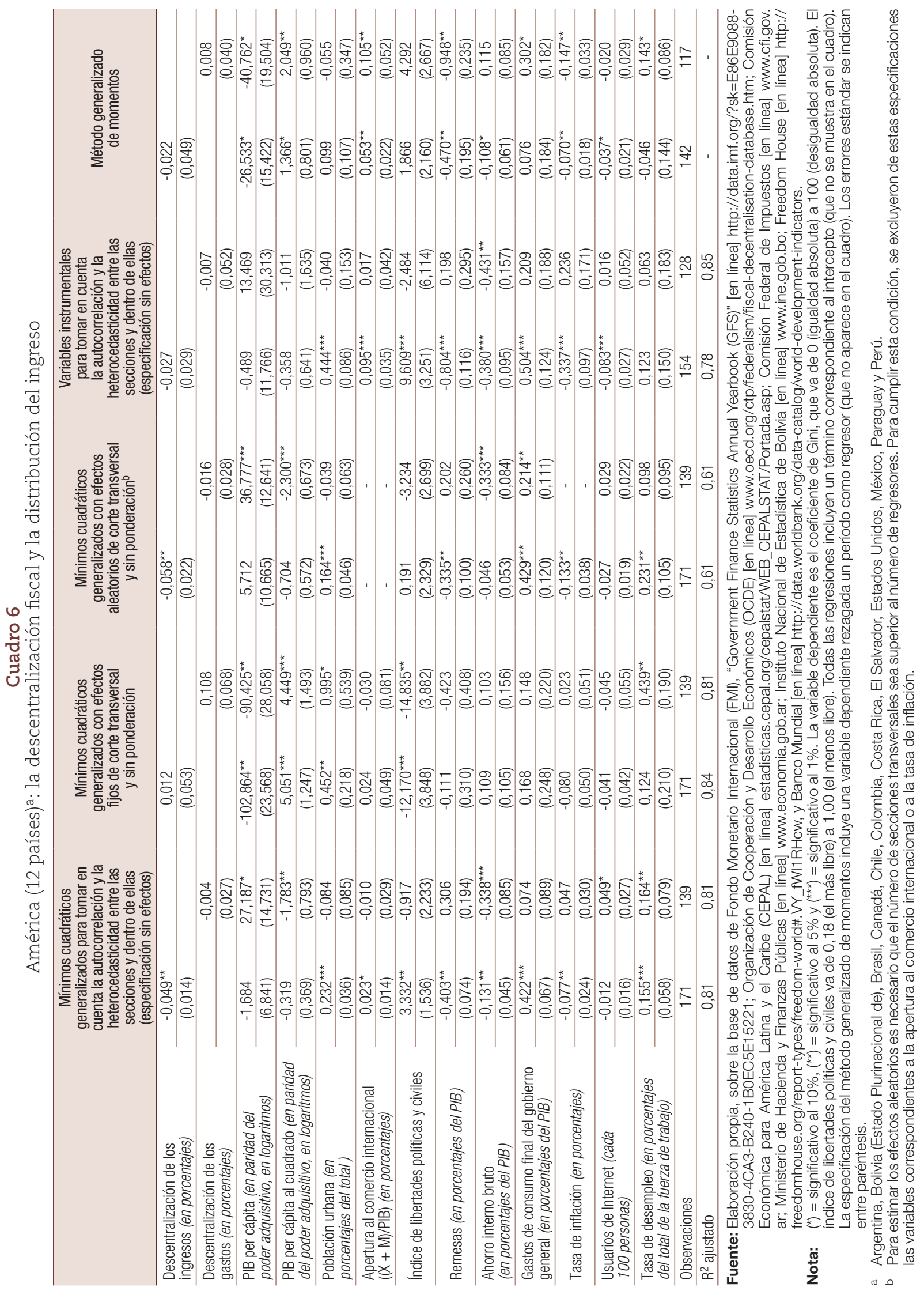




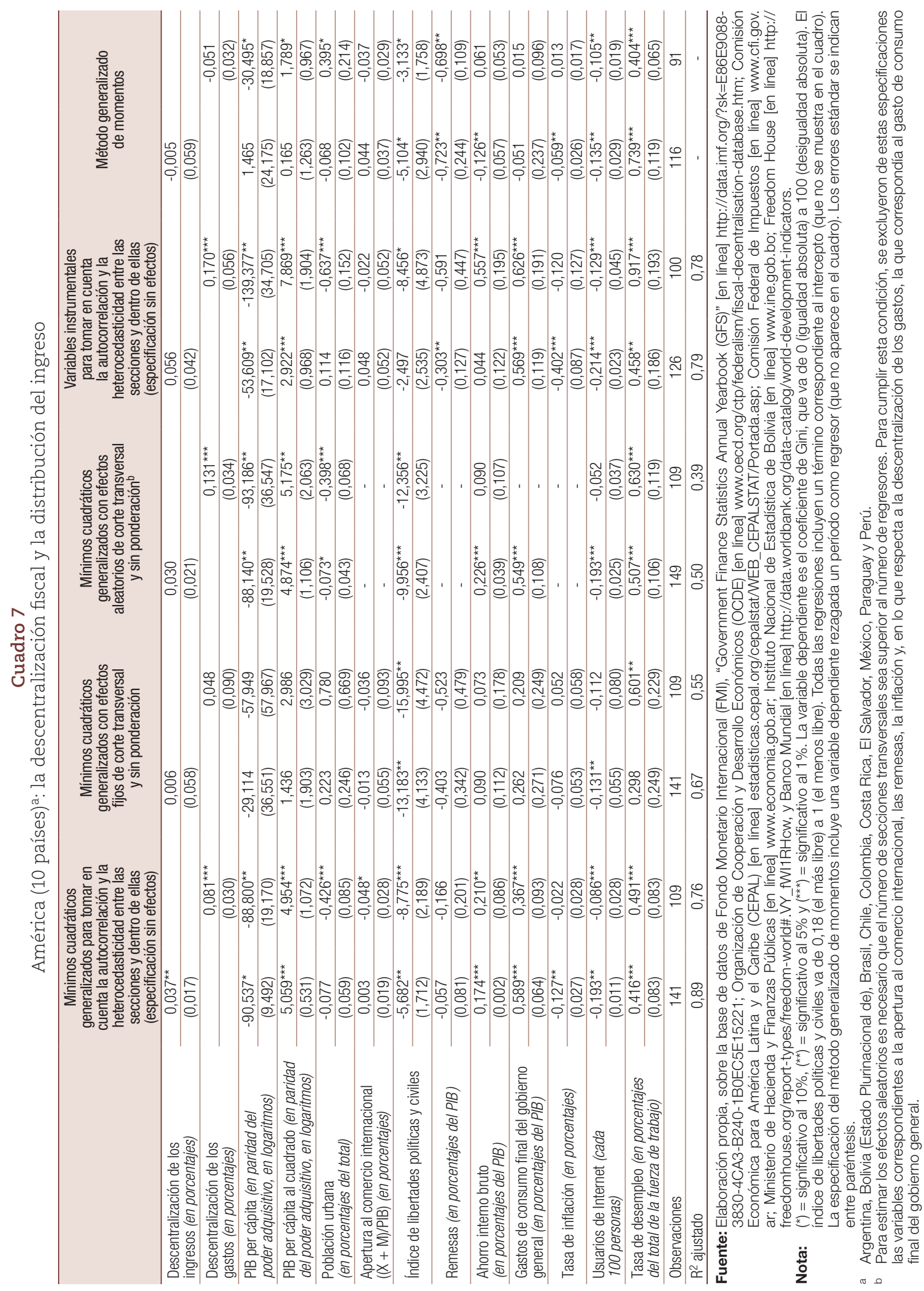


El efecto de la descentralización fiscal en el coeficiente de Gini es más claro con este subconjunto de países de América. De forma sistemática, los dos indicadores de descentralización son positivos, de tamaño similar y, en varios casos, estadísticamente significativos, lo que sugiere que, en realidad, la descentralización puede contribuir a una mayor desigualdad en los países en desarrollo de América. Si bien esta inferencia parece ser más sólida cuando la descentralización se refiere a los gastos, en ambos casos la conclusión general parece ser que no se ha cumplido la promesa de que la descentralización fiscal contribuiría a una mayor igualdad de los ingresos en esos países. Esto, como Brosio y Jiménez (2013) señalan con razón, pone de relieve la necesidad de reforzar los mecanismos de coordinación y los acuerdos entre todos los niveles de gobierno, a fin de mejorar la eficiencia y la obtención de resultados en las estructuras de descentralización de esos países.

Con respecto al comportamiento de las variables de control, el PIB per cápita parece contribuir al principio a una mayor igualdad de los ingresos, pero con el tiempo a una mayor desigualdad. Esto es lo que indican los coeficientes siempre positivos y estadísticamente significativos del PIB per cápita al cuadrado, hecho que con claridad va en contra de la predicción de Kuznets. El aumento de la urbanización, las remesas y el acceso a Internet son factores importantes que contribuyen a una mayor igualdad de los ingresos, como se observa en los coeficientes que, de forma sistemática, son negativos y estadísticamente significativos. Esto pone de relieve la importancia de los entornos urbanos, la participación de la diáspora y el acceso a la Web como factores clave para reducir la desigualdad de los ingresos en los países en desarrollo. El mayor tamaño del gobierno y el aumento del desempleo, por otra parte, al parecer favorecen una mayor desigualdad de los ingresos, como lo indican los coeficientes que constantemente son positivos y estadísticamente significativos. Esto demuestra que es la calidad y no el tamaño del gobierno lo que determina su productividad, y pone de relieve el hecho bien documentado de que el desempleo siempre suele empeorar las cosas. Como ocurría con la muestra completa de países, y por los mismos motivos, la inflación también parece tener un efecto mitigador de la desigualdad, mientras que el ahorro puede contribuir a una mayor desigualdad, quizás porque en los países en desarrollo de América solo una minoría es capaz de ahorrar, mientras que la mayoría sencillamente no puede aplazar el consumo actual. Un resultado curioso es el efecto que las libertades políticas y civiles al parecer tienen sobre la desigualdad de los ingresos en esos países. Los valores correspondientes al índice de libertades políticas y civiles, que de forma sistemática son negativos y estadísticamente significativos, al parecer sugieren que, cuantas menos libertades políticas y civiles hay, mayor es la igualdad de los ingresos. Es posible que este resultado refleje la percepción que hay en muchos países en desarrollo de América de que a menudo se necesitan gobiernos fuertes para aprobar leyes necesarias que tal vez no sean populares al principio, pero que, con el tiempo, producen beneficios, como una mayor igualdad de los ingresos. Por último, hay algunos indicios de que la apertura económica mitiga la desigualdad de los ingresos.

\section{Conclusiones y consecuencias en materia de políticas}

En este artículo se analiza el efecto de la descentralización fiscal en el crecimiento económico, la inflación y la desigualdad de los ingresos en una muestra de países de América. Habida cuenta de que, en los últimos años, en la mayoría de estos países se ha atravesado un período de descentralización gradual de las funciones económicas hacia los niveles regionales de gobierno, los resultados que se presentan aquí resultan oportunos y pertinentes.

Las principales conclusiones son las que se indican a continuación. Con respecto al efecto de la descentralización fiscal sobre el crecimiento económico cuando todos los países se incluyen en el análisis, el indicador de la descentralización de los ingresos muestra de forma sistemática un efecto 
negativo en el crecimiento. En lo que respecta a la descentralización de los gastos, las pruebas no son concluyentes y, por lo tanto, no se puede determinar si esta ha tenido un efecto positivo o negativo en el crecimiento. Cuando el mismo análisis se lleva a cabo sin el Canadá y los Estados Unidos, se observa de forma constante que la descentralización de los ingresos ejerce una influencia negativa sobre el crecimiento, lo que confirma los resultados que se obtuvieron con la muestra completa de países. El indicador correspondiente a la descentralización de los gastos, no obstante, parece tener un efecto positivo en el crecimiento, lo que demuestra que este tipo de descentralización es más propicia para el crecimiento en los países en desarrollo de América. Las variables de control se comportan de manera similar sin importar qué muestra de países se analice. Por ejemplo, se observa de forma sistemática que el ahorro nacional contribuye al crecimiento, mientras que el mayor desempleo, el aumento del tamaño del gobierno y la mayor apertura al comercio lo reducen. El efecto del resto de las variables de control no es tan claro, y, por ende, su efecto combinado sobre el crecimiento es indefinido.

Con respecto a cómo repercute la descentralización fiscal en la inflación, los resultados son indeterminados, sin importar qué muestra de países se analice ni si la descentralización atañe a los ingresos o a los gastos. En ningún caso es posible discernir una pauta de comportamiento que permita extraer conclusiones inequívocas sobre la forma en que la descentralización afecta la estabilidad de los precios. Las variables de control se comportan de la misma manera en ambas series de regresiones, si bien el efecto de esas variables es un poco más claro en la muestra de países en la que se excluyen el Canadá y los Estados Unidos. Un resultado digno de mención es que, si bien el gasto público en ambas muestras de países en general parece atenuar la inflación, el gasto militar al parecer tiene un efecto más inflacionario en la muestra de países en desarrollo de América, lo que pone de relieve la necesidad de gestionar con cuidado este tipo de gasto. El impacto del resto de las variables de control no es concluyente.

Por último, en lo que respecta a cómo repercute la descentralización fiscal en el coeficiente de Gini, si se tiene en cuenta la muestra que abarca la totalidad de los países, los resultados indican que la descentralización de los ingresos tiene los efectos positivos previstos en cuanto a la reducción de la desigualdad de los ingresos. Esto se refleja en los coeficientes sistemáticamente negativos y estadísticamente significativos de las estimaciones en las que se utilizan los MCG (especificaciones de MCG calculadas sin efectos y con efectos aleatorios), que señalan la importancia de la descentralización fiscal y sus posibles beneficios en cuanto a la reducción de las disparidades en materia de ingresos. En lo que respecta a los gastos, sin embargo, no hay pruebas de que la descentralización haya desempeñado algún papel en la mitigación de la desigualdad de los ingresos.

El efecto de la descentralización fiscal en la variable dependiente es algo más claro cuando se excluyen el Canadá y los Estados Unidos, ya sea que la descentralización ataña a los ingresos o a los gastos. Los indicadores de descentralización fiscal son en general positivos y, en algunos casos, estadísticamente significativos (especificaciones de MCG sin efectos y con efectos aleatorios, y variables instrumentales sin efectos), lo que demuestra que la descentralización fiscal no ha desempeñado el papel que se esperaba en la reducción de la desigualdad de los ingresos en los países en desarrollo de América.

Con respecto al comportamiento de las variables de control, los resultados son dispares. El impacto del PIB per cápita (en niveles o en valores al cuadrado) no es claro cuando se observa la muestra completa de países. No obstante, cuando se observan solo los países en desarrollo de América, al parecer en un principio disminuye la desigualdad de los ingresos, pero la empeora con el correr del tiempo. En apariencia, la mayor urbanización reduce la desigualdad de los ingresos en los países en desarrollo de América en casi todos los casos, pero, cuando en la muestra se incluyen el Canadá y los Estados Unidos, parece ocurrir lo contrario. En todos los casos, las remesas y la inflación reducen la desigualdad de los ingresos, mientras que el desempleo y el mayor tamaño del 
gobierno la empeora. La apertura al comercio parece aumentar las desigualdades en el caso de la muestra completa de países, pero hay indicios de que puede mitigarla cuando solo se consideran los países en desarrollo. El ahorro al parecer reduce la desigualdad en la muestra completa de países, y la aumenta cuando se excluyen el Canadá y los Estados Unidos. El acceso a Internet disminuye la desigualdad en los países en desarrollo de América, pero su efecto en la muestra completa de países es poco claro. Por último, el que los derechos políticos y civiles sean débiles al parecer propicia más el crecimiento solo en los países en desarrollo de América, mientras que los efectos sobre la muestra completa de países son indefinidos.

En lo que respecta a las políticas, la consecuencia más importante de las conclusiones que aquí se presentan es que, hasta el momento, la descentralización fiscal no ha cumplido con las expectativas en relación con sus efectos sobre el crecimiento, la estabilidad de los precios y la distribución del ingreso. Aunque hay algunos indicios de que la descentralización puede incidir de forma positiva en el crecimiento, en particular cuando afecta los gastos, se suponía que iba a ser un potente catalizador de este último. Asimismo, se planteaba que la descentralización fiscal actuaría como elemento disuasorio de la mala gestión fiscal y, por tanto, contrarrestaría las presiones inflacionarias, pero aún no hay pruebas al respecto. Por último, se suponía que ese proceso conduciría a una mayor igualdad de los ingresos y, aunque hay datos de que esto ha comenzado a ocurrir (cuando se considera la muestra completa de países y la descentralización atañe a los ingresos), también hay indicios de que queda mucho por hacer para lograr este objetivo. La recomendación principal, en particular desde la perspectiva de los países en desarrollo de América, es que deben fortalecerse la capacidad institucional de los niveles subnacionales de gobierno y los mecanismos de coordinación entre los diferentes niveles. Con una mayor capacidad institucional y una mejor coordinación entre todos los niveles de gobierno, quizás comiencen a concretarse los resultados positivos que se preveían en relación con este proceso.

\section{Bibliografía}

Amagoh, F. y A. A. Amin (2012), "An examination of the impacts of fiscal decentralization on economic growth", International Journal of Business Administration, vol. 3, № 6, Sciedu Press.

Baskaran, T. y L. P. Feld (2013), "Fiscal decentralization and economic growth in OECD countries: is there a relationship?", Public Finance Review, vol. 41, № 4, SAGE.

Beramendi, P. (2003), "Political institutions and income inequality: the case of decentralization", WZB, Markets and Political Economy Working Paper, № SP II 2003-09 [en línea] http://ssrn.com/abstract=473701.

Blöchliger, H. (2013), "Decentralization and economic growth - Part 1: how fiscal federalism affects long-term development", OECD Working Papers on Fiscal Federalism, № 14, París, OECD Publishing [en línea] http://dx.doi.org/10.1787/5k4559gx1g8r-en.

Bodman, P. y otros (2009), "Fiscal decentralisation, macroeconomic conditions and economic growth in Australia", Macroeconomics Research Group Working Paper, № 2609, Universidad de Queensland [en línea] www.uq.edu.au/economics/mrg/2609.pdf.

Boex, J. y otros (2006), "Fighting Poverty through Fiscal Decentralization”, Washington, D.C., Agencia de los Estados Unidos para el Desarrollo Internacional (USAID) [en línea] http://pdf.usaid.gov/pdf_docs/ PNADH105.pdf.

Bojanic, A. N. (2016), "Fiscal decentralization, economic freedom, and political and civil liberties in the Americas", Working Paper, № 1609, Universidad de Tulane [en línea] http://ideas.repec.org/p/tul/wpaper/1609.html.

Brosio, G. y J. P. Jiménez (2013), Decentralization and Reform in Latin America: Improving Intergovernmental Relations, Northampton, Edward Elgar Publishing.

Brueckner, J. K. (2005), "Fiscal federalism and economic growth", CESifo Working Paper Series, № 1601 [en línea] www.econstor.edu/bitstream/10419/19065/1/cesifo1_wp1601.pdf.

Cavusoglu, T. y O. Dincer (2015), "Does decentralization reduce income inequality? Only in rich States", Southern Economic Journal, vol. 82, N 1, Wiley. 
Davoodi, H. y H. Zou (1998), "Fiscal decentralization and economic growth: a cross-country study", Journal of Urban Economics, vol. 43, $\mathrm{N}^{\circ} 2$, Amsterdam, Elsevier.

Durham, J. B. (1999), "Econometrics of income distribution: toward more comprehensive specification of institutional correlates", Comparative Economic Studies, vol. 41, N 1, Springer.

Gemmell, N., R. Kneller e I. Sanz (2013), "Fiscal decentralization and economic growth: spending versus revenue decentralization", Economic Inquiry, vol. 51, N 4, Wiley.

Goerl, C. y M. Seiferling (2014), "Income inequality, fiscal decentralization and transfer dependency", IMF Working Paper, N 14/64, Washington, D.C., Fondo Monetario Internacional (FMI) [en línea] http://www. imf.org/external/pubs/ft/wp/2014/wp1464.pdf.

lqbal, N. y S. Nawaz (2010), "Fiscal decentralization and macroeconomic stability: theory and evidence from Pakistan”, MPRA Paper, Nº 27184 [en línea] http://mpra.ub.uni-muenchen.de/27184/.

Islam, F. (2015), "The role of local self-government institution for deepening democracy at the grass-root level in Bangladesh", Journal of Public Administration and Policy Research, vol. 7, № 2.

Jalil, A. Z., M. Harun y S. H. Che Mat (2012), "Macroeconomic instability and fiscal decentralization: an empirical analysis", Prague Economic Papers, №2, Praga, Universidad de Economía de Praga.

Kaufman, H. (1969), "Administrative decentralization and political power", Public Administration Review, vol. 29, N¹, Wiley.

Kuznets, S. (1955), "Economic growth and income inequality", American Economic Review, vol. 45, № 1, Nashville, Tennessee, American Economic Association.

Lee, C. (2005), "Income inequality, democracy, and public sector size", American Sociological Review, vol. 70, N 1 , SAGE.

Martínez, R., L. Ayala y J. Ruiz-Huerta (2001), "The impact of unemployment on inequality and poverty in OECD countries", Economics of Transition, vol. 9, N², Wiley.

Martínez-Vázquez, J. y R. M. McNab (2006), "Fiscal decentralization, macrostability, and growth", Hacienda Pública Española/Revista de Economía Pública, vol. 179, № 4, Madrid, Instituto de Estudios Fiscales. (2003), "Fiscal decentralization and economic growth", World Development, vol. 31, N 9 , Amsterdam, Elsevier.

Michels, A. (2011), "Innovations in democratic governance: how does citizen participation contribute to a better democracy?", International Review of Administrative Sciences, vol. 77, № 2, SAGE.

Monnin, P. (2014), "Inflation and income inequality in developed economies", CEP Working Paper, N²014/1, Council on Economic Policies [en línea] http://www.cepweb.org/wp-content/uploads/2014/05/CEP_WP_ Inflation_and_Income_Inequality.pdf.

Moon, H. (2003), "Regional Inequality and Fiscal Decentralization in Korea: Evaluation and Policy Implications", Instituto Coreano de Desarrollo [en línea] www.kdi.re.kr/upload/7050/IV_HyungpyoMoon.pdf.

Neyapti, B. (2010), "Fiscal decentralization and deficits: international evidence", European Journal of Political Economy, vol. 26, №2, Amsterdam, Elsevier.

(2004), "Fiscal decentralization, central bank independence and inflation: a panel investigation", Economic Letters, vol. 82, N², Amsterdam, Elsevier.

Oates, W. (1993), "Fiscal decentralization and economic development", National Tax Journal, vol. 46, № 2, National Tax Association.

Okonkwo, O. N. y E. K. Godslove (2015), "Fiscal decentralization and Nigerian macroeconomic performance and economic stability", International Journal of Economics and Finance, vol. 7, № 2, Canadian Center of Science and Education.

Rao, M. G. (2000), "Fiscal Decentralization in Indian Federalism" [en línea] https://www.imf.org/external/pubs/ $\mathrm{ft} /$ seminar/2000/fiscal/rao.pdf.

Rodden, J., G. Eskeland y J. Litvack (2003), Fiscal Decentralization and the Challenge of Hard Budget Constraints, Cambridge, Massachusetts, The MIT Press.

Rodríguez, F. y D. Rodrik (1999), "Trade policy and economic growth: a skeptic's guide to cross-national evidence”, NBER Working Paper, № 7081, Cambridge, Massachusetts, Oficina Nacional de Investigaciones Económicas [en línea] www.nber.org/papers/w7081.

Rodríguez-Pose, A. y R. Ezcurra (2011), "Is fiscal decentralization harmful for economic growth? Evidence from the OECD countries", Journal of Economic Geography, vol. 11, N 4, Oxford University Press.

Sacchi, A. y S. Salotti (2014), "The effects of fiscal decentralization on household income inequality: some empirical evidence", Spatial Economic Analysis, vol. 9, N², Taylor \& Francis.

Sepúlveda, C. y J. Martínez-Vázquez (2011), "The consequences of fiscal decentralization on poverty and income inequality", Environment and Planning C: Government and Policy, vol. 29, № 2, Londres, Pion. 
Song, Y. (2013), "Rising Chinese regional income inequality: the role of fiscal decentralization", China Economic Review, vol. 27, Amsterdam, Elsevier.

Thornton, J. (2007), "Fiscal decentralization and economic growth revisited", Journal of Urban Economics, vol. 61, № 1, Amsterdam, Elsevier.

Treisman, D. (2000), "Decentralization and inflation: commitment, collective action, or continuity?", American Political Science Review, vol. 94, № 4, American Political Science Association.

Weingast, B. R. (2009), "Second generation fiscal federalism: the implications of fiscal incentives", Journal of Urban Economics, vol. 65, № 3, Amsterdam, Elsevier.

Xie, D., H. Zou y H. Davoodi (1999), "Fiscal decentralization and economic growth in the United States", Journal of Urban Economics, vol. 45, №2, Amsterdam, Elsevier.

Yifu Lin, J. y Z. Liu (2000), "Fiscal decentralization and economic growth in China", Economic Development and Cultural Change, vol. 49, N 1, Chicago, The University of Chicago Press. 